\title{
Effect of spontaneous breathing on ventilator-free days in critically ill patients - an analysis of patients in a large observational cohort
}

\author{
Aline Mela Dos Reis ${ }^{1}$, Thais Dias Midega ${ }^{1}$, Rodrigo Octavio Deliberato ${ }^{1,2}$, Alistair EW Johnson ${ }^{3}$, \\ Lucas Bulgarelli, $^{2,3}$, Thiago Domingos Correa ${ }^{1}$, Leo Anthony Celi ${ }^{3,4}$, Paolo Pelosi ${ }^{5,6}$, Marcelo Gama de Abreu ${ }^{7}$, \\ Marcus J. Schultz ${ }^{8,9,10}$, Ary Serpa Neto ${ }^{1,8,11,12}$; for the PROVE Network investigators*
}

${ }^{1}$ Department of Critical Care Medicine, Hospital Israelita Albert Einstein, São Paulo, Brazil; ${ }^{2}$ Big Data Analytics Group, Hospital Israelita Albert Einstein, São Paulo, Brazil; ${ }^{3}$ Laboratory for Computational Physiology, Institute for Medical Engineering \& Science, MIT, Cambridge, MA, USA; ${ }^{4}$ Division of Pulmonary, Critical Care and Sleep Medicine, Beth Israel Deaconess Medical Center, Boston, MA, USA; ${ }^{5}$ IRCCS San Martino Policlinico Hospital, Genoa, Italy; ${ }^{6}$ Department of Surgical Sciences and Integrated Diagnostics (DISC), University of Genoa, Genoa, Italy; ${ }^{7}$ Pulmonary Engineering Group, Department of Anesthesiology and Intensive Care Medicine, University Hospital Carl Gustav Carus, Technical University Dresden, Dresden, Germany; ${ }^{8}$ Department of Intensive Care \& 'Laboratory of Experimental Intensive Care and Anesthesiology' (L.E.I.C.A), Academic Medical Center, Amsterdam, The Netherlands; ${ }^{9}$ Mahidol-Oxford Tropical Medicine Research Unit (MORU), Faculty of Tropical Medicine, Mahidol University, Bangkok, Thailand; ${ }^{10}$ Nuffield Department of Medicine, University of Oxford, Oxford, UK; ${ }^{11}$ Australian and New Zealand Intensive Care Research Centre, Monash University, Melbourne, Australia; ${ }^{12}$ Data Analytics Research \& Evaluation (DARE) Centre, Austin Hospital and University of Melbourne, Melbourne, Australia

Contributions: (I) Conception and design: AMD Reis, A Serpa Neto; (II) Administrative support: A Serpa Neto, LA Celi, M Gama de Abreu, P Pelosi, MJ Schultz; (III) Provision of study materials or patients: AMD Reis, RO Deliberato, AEW Johnson, L Bulgarelli, LA Celi; (IV) Collection and assembly of data: AMD Reis, RO Deliberato, AEW Johnson, L Bulgarelli, LA Celi; (V) Data analysis and interpretation: AMD Reis, TD Midega, A Serpa Neto; (VI) Manuscript writing: All authors; (VII) Final approval of manuscript: All authors.

Correspondence to: Ary Serpa Neto, MD, MSc, PhD. Australian and New Zealand Intensive Care Research Centre, Monash University, Level 3, 553 St. Kilda Rd., Melbourne, VIC 3004, Australia. Email: ary.serpaneto@monash.edu.

Background: Mechanical ventilation can injure lung tissue and respiratory muscles. The aim of the present study is to assess the effect of the amount of spontaneous breathing during mechanical ventilation on patient outcomes.

Methods: This is an analysis of the database of the 'Medical Information Mart for Intensive Care (MIMIC)'-III, considering intensive care units (ICUs) of the Beth Israel Deaconess Medical Center (BIDMC), Boston, MA. Adult patients who received invasive ventilation for at least 48 hours were included. Patients were categorized according to the amount of spontaneous breathing, i.e., $\geq 50 \%$ ('high spontaneous breathing') and $<50 \%$ ('low spontaneous breathing') of time during first 48 hours of ventilation. The primary outcome was the number of ventilator-free days.

Results: In total, the analysis included 3,380 patients; $70.2 \%$ were classified as 'high spontaneous breathing', and $29.8 \%$ as 'low spontaneous breathing'. Patients in the 'high spontaneous breathing' group were older, had more comorbidities, and lower severity scores. In adjusted analysis, the amount of spontaneous breathing was not associated with the number of ventilator-free days [20.0 (0.0-24.2) vs. 19.0 (0.0-23.7) in high vs. low; absolute difference, 0.54 (95\% CI, -0.10 to 1.19$) ; \mathrm{P}=0.101$ ]. However, 'high spontaneous breathing' was associated with shorter duration of ventilation in survivors [6.5 (3.6 to 12.2) vs. 7.6 (4.1 to 13.9); absolute difference, -0.91 (95\% CI, -1.80 to -0.02 ); $\mathrm{P}=0.046$ ].

Conclusions: In patients surviving and receiving ventilation for at least 48 hours, the amount of spontaneous breathing during this period was not associated with an increased number of ventilator-free days.

Keywords: Mechanical ventilation; tidal volume; spontaneous breathing; acute respiratory distress syndrome

* PROtective VEntilation (PROVE Network) (http://www.provenet.eu). 
(ARDS); positive end-expiratory pressure (PEEP); ventilator-induced lung injury

Submitted Dec 09, 2020. Accepted for publication Jan 22, 2021.

doi: $10.21037 /$ atm-20-7901

View this article at: http://dx.doi.org/10.21037/atm-20-7901

\section{Introduction}

Mechanical ventilation has a strong potential to harm lung tissue and respiratory muscles. Prevention of lung injury translates to improved survival, shorter need for mechanical ventilation, and reduced length of stay in the intensive care unit (ICU) and hospital (1-3). One proven effective measure against ventilator-induced lung injury is the use of an adequately-sized, i.e., low tidal volume $\left(\mathrm{V}_{\mathrm{T}}\right)$ (4-6). Maintaining respiratory muscle activity may prevent ventilator-induced diaphragm dysfunction $(1,7)$.

There is a clear trend towards a preference for assisted over controlled modes of ventilation. Use of assisted ventilation which allows spontaneous breaths may not only reduce the risk of lung injury by additional recruitment of non-aerated areas, but also keeps a patient's diaphragm active $(2,8,9)$. However, assisted ventilation may also result in high inspiratory efforts and a higher respiratory drive, which can potentially increase lung injury (10). Thus, it remains uncertain whether increased use of spontaneous breathing translates into clinical benefit. The results of a recent posthoc analysis of a large observational study in acute respiratory distress syndrome (ARDS) patients suggests that spontaneous breathing in the first days of ventilation does not impact survival but hastens liberation from the ventilator (9).

To gain a better understanding of the effect of the amount of spontaneous breathing on outcome in critically ill patients who received mechanical ventilation for various reasons, the 'Medical Information Mart for Intensive Care (MIMIC)'-III was analyzed. The primary hypothesis tested was that the amount of spontaneous breathing is associated with an increased number of ventilator-free days at day 28 in patients surviving and receiving mechanical ventilation for at least 48 hours. We present the following article in accordance with the STROBE reporting checklist (available at http://dx.doi.org/10.21037/atm-20-7901).

\section{Methods}

\section{Study design and ethical concerns}

This is a retrospective analysis of the MIMIC-III database that contains high-resolution clinical data from patients admitted to the ICUs of the Beth Israel Deaconess Medical Center (BIDMC), Boston, MA $(11,12)$. The data in MIMIC-III has been previously de-identified, and the study was conducted in accordance with the Declaration of Helsinki (as revised in 2013) and approved by the institutional review boards of the Massachusetts Institute of Technology (No. 0403000206) and Beth Israel Deaconess Medical Center (2001-P-001699/14). Due to the study's retrospective nature, the requirement for individual consent was waived.

\section{Inclusion and exclusion criteria}

Patients in the MIMIC-III version v1.4 database were selected for the current analysis if: (I) age $\geq 16$ years; and (II) they received mechanical ventilation for at least 48 consecutive hours. Patients who received ventilation through a tracheostomy cannula at any time during the first 48 hours of ventilation. Only data of the first ICU admission of the first hospitalization were included. Patients transferred from other hospitals were considered only when mechanical ventilation started in the final hospital.

\section{Data extraction and preparation}

The dataset was assessed for completeness and consistency; outliers, defined as observations that lied outside $1.5 \times$ interquartile range (IQR), were checked and substituted by the $5^{\text {th }}$ or $95^{\text {th }}$ percentile (13). Ventilatory variables were extracted as the highest and the lowest values per each timeframe of six hours during the first 48 hours of ventilation. These values were summarized as the mean for every 6-hour time window.

The ventilation modes were extracted per each timeframe of six hours during the first 48 hours of ventilation. The classification of the ventilation modes that was used for the longest time in each time-frame follows the categorization in previous studies $(14,15)$, as follows:

* Modes mandating spontaneous breathing: in these modes spontaneous breathing is always required, 
i.e., the ventilator will never provide a breath when the patient does not trigger the ventilator [e.g., 'continuous positive airway pressure' (CPAP), 'proportional assisted ventilation' (PAV) or 'pressure support ventilation' (PSV)]; and

* Modes allowing spontaneous breathing: spontaneous breathing is possible, but when the patient does not trigger the ventilator, only controlled breaths will be delivered [e.g., 'pressure-controlled ventilation' (PCV) or 'volume-controlled ventilation' (VCV)].

For details, see Tables S1,S2.

\section{Definitions}

For every 6 hours during the first 48 hours of ventilation, it was defined whether a patient was spontaneous breathing, as follows:

* A patient was considered not to have spontaneous breathing if set respiratory rate (RR) equaled the total RR, and

* A patient was considered to have spontaneous breathing if receiving a ventilation mode mandating spontaneous breathing, or if set RR was lower than the total RR.

Then each patient was classified as follows:

* Breathing spontaneously for equal or more than $50 \%$ of the time (high spontaneous breathing' patients), if the proportion of time with spontaneous breathing was $\geq 50 \%$ in the first 48 hours of ventilation; and

- Breathing spontaneous for less than $50 \%$ of the time ('low spontaneous breathing' patients), if the proportion of time with spontaneous breathing was $<50 \%$ in the first 48 hours of ventilation.

\section{Outcomes}

The primary outcome was the number of ventilator-free days, defined as the number of days from successfully weaning to day 28; patients who died before weaning were deemed to have no ventilator-free days. Secondary outcomes included duration of ventilation in survivors, ICU-, hospital and 30-day mortality, and ICU- and hospital length of stay.

\section{Power calculation}

No formal sample size calculation was carried out, and all patients included in the current version of the dataset were eligible for inclusion.

\section{Statistical analysis}

Only complete case analysis was carried out and no assumption for missing data was done. All patients were followed until hospital discharge or death. Continuous variables are presented as medians with their interquartile ranges and categorical variables as total number and percentage. Proportions were compared using $\chi^{2}$ or Fisher exact tests and continuous variables were compared using the $t$ test or Wilcoxon rank sum test, as appropriate.

$\mathrm{V}_{\mathrm{T}}$ size was collected as an absolute volume $(\mathrm{mL})$ and then normalized for predicted body weight ( $\mathrm{mL} / \mathrm{kg}$ PBW). The PBW was calculated as equal to $50+0.91$ (centimeters of height 152.4) in males, and 45.5+0.91 (centimeters of height 152.4) in females (16). Presence of the acute respiratory distress syndrome (ARDS) in the first 48 hours of ventilation was scored according to current definition for ARDS, the Berlin Definition, which means that all patients had to be reclassified when previous definitions or criteria were used (17).

All main analyses were performed using mixed-effect models to account for within-year clustering. Heterogeneity between years was determined by fitting a fixed interaction term between the variable of interest and year of admission as continuous variable, while overall effect of the comparison of 'high spontaneous breathing' with 'low spontaneous breathing' patients was reported with year of admission treat as a random effect.

In a first assessment, group assignment ('high spontaneous breathing' vs. 'low spontaneous breathing') was entered in a mixed-effect multivariable model adjusted for relevant covariates known to predict outcome (description in the Supplementary File). The variable of interest was forced in the models as it were the main focus of the study.

As the use and the effect of spontaneous breathing could vary according to baseline characteristics and severity of the patients, the following subgroups were assessed: (I) ARDS vs. non-ARDS in the first $48 \mathrm{~h}$; (II) low tidal volume ventilation (LTVV) vs. non-LTVV, with LTTV defined as a median tidal volume $\leq 8 \mathrm{~mL} / \mathrm{kg} \mathrm{PBW}$ in the first 48 hours of ventilation; and (III) baseline $\mathrm{PaO}_{2} / \mathrm{FiO}_{2} \leq 250$ vs. $\mathrm{PaO}_{2} /$ $\mathrm{FiO}_{2}>250$. To determine if the relationship between group and the primary outcome differs between the subgroups, fixed interaction terms between treatment and subgroup were added in the adjusted models for the primary outcome described above. To further ascertain if the treatment- 
subgroup interaction varied between the year of admission, a three-way fixed interaction between year, treatment and subgroup were also reported.

To address heterogeneity of treatment effect, the models described above were re-assessed in two groups using stricter definitions, as follows:

* exclusively breathing spontaneously ('always spontaneous breathing' patients), if the proportion of time with spontaneous breathing was $100 \%$ in the first 48 hours of ventilation; and

* never breathing spontaneous ('never spontaneous breathing' patients), if the proportion of time with spontaneous breathing was $0 \%$ in the first 48 hours of ventilation.

Statistical significance was considered to be at two-sided $\mathrm{P}<0.05$. All analyses were performed with $\mathrm{R}$ v.3.6.0 (www. R-project.org).

\section{Results}

\section{Patients}

From 2001 until 2012, 3,380 patients were selected for the current analysis, 2,374 (70\%) were classified as 'high spontaneous breathing' patients, and 1,006 (30\%) as 'low spontaneous breathing' patients (Figure S1). Baseline characteristics are shown in Table 1 and Table S3. 'High spontaneous breathing' patients were older, had more comorbidities, lower SOFA scores and less often needing vasopressors. Ventilation data are presented in Table 2, Figure 1, and Figure S2. In the first two days of ventilation, $\mathrm{V}_{\mathrm{T}}$ was similar while PEEP, peak pressure and driving pressure were lower in 'high spontaneous breathing' patients.

\section{The primary endpoint}

Clinical outcomes are presented in Table 3 and Table S4. Both in unadjusted and adjusted analysis, the number of ventilator-free days was not different between the two groups $\{20.0$ (0.0 to 24.2$)$ vs. 19.0 (0.0 to 23.7) in 'high spontaneous breathing' vs. 'low spontaneous breathing' patients, respectively; absolute difference, 0.19 [95\% confidence interval (CI), -0.59 to 0.97$] ; \mathrm{P}=0.635$, and 20.0 (0.0 to 24.2) vs. 19.0 (0.0 to 23.7); absolute difference, 0.54 (95\% CI, -0.10 to 1.19$) ; \mathrm{P}=0.101\}$.

\section{Secondary endpoints}

In unadjusted analysis, 'high spontaneous breathing' patients had a shorter duration of ventilation and a shorter ICU length of stay. In the adjusted analysis, only duration of ventilation remained lower in 'high spontaneous breathing' patients.

\section{Subgroup analyses}

Results of the subgroup analyses are present in Figure S3. There was no interaction among any of the subgroups and 'high spontaneous breathing' patients.

\section{Additional analysis}

Of all patients available, 1,809 (53.5\%) were classified as 'always spontaneous breathing' patients, and 755 (22.3\%) as 'never spontaneous breathing' patients. Baseline characteristics, vital signs and laboratory tests, and ventilation data in 'always spontaneous breathing' patients and 'never spontaneous breathing' patients are shown in Tables S5-S7, and Figures S4,S5.

In unadjusted analysis, ICU length of stay was different between 'always spontaneous breathing' patients and 'never spontaneous breathing' patients (Table S8). In the adjusted analysis, ventilator-free days was higher in 'always spontaneous breathing' patients (Table S9).

\section{Discussion}

The results of this retrospective analysis of the database of a large cohort of mechanically ventilated ICU patients surviving and receiving ventilation for at least 48 hours can be summarized as follows: (I) many patients breath spontaneously for more than $50 \%$ of the time within the first 48 hours of invasive ventilation; (II) the proportion of spontaneous breathing in the first 48 hours is not associated with the number of ventilator-free days when one compares high $v s$. low spontaneous breathing; (III) but this proportion is associated with a shorter duration of ventilation among survivors. In addition, (IV) 'always spontaneous breathing' is associated with more ventilator-free days.

The main strength of this analysis is the comprehensive and high-resolution data capture throughout the hospital course of a large group of well-defined and characterized ICU patients. By excluding patients who were breathing through a tracheostomy in the first 48 hours, we avoided the inclusion of patients receiving long-term mechanical ventilation prior to the hospitalization, and those expecting to receive long-term mechanical ventilation (e.g., patients 
Table 1 Baseline characteristics of the included patients according to the groups

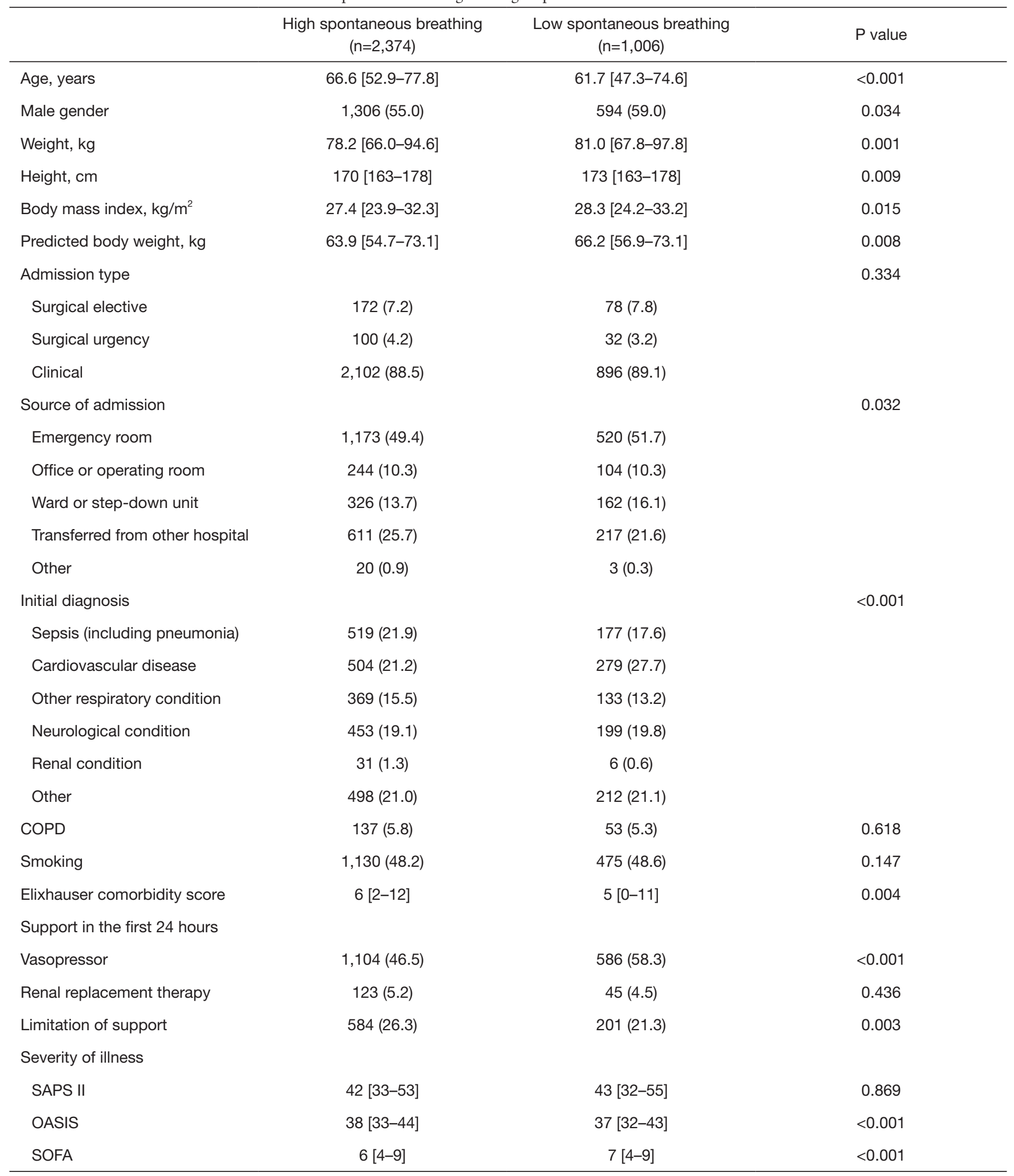

Table 1 (continued) 
Table 1 (continued)

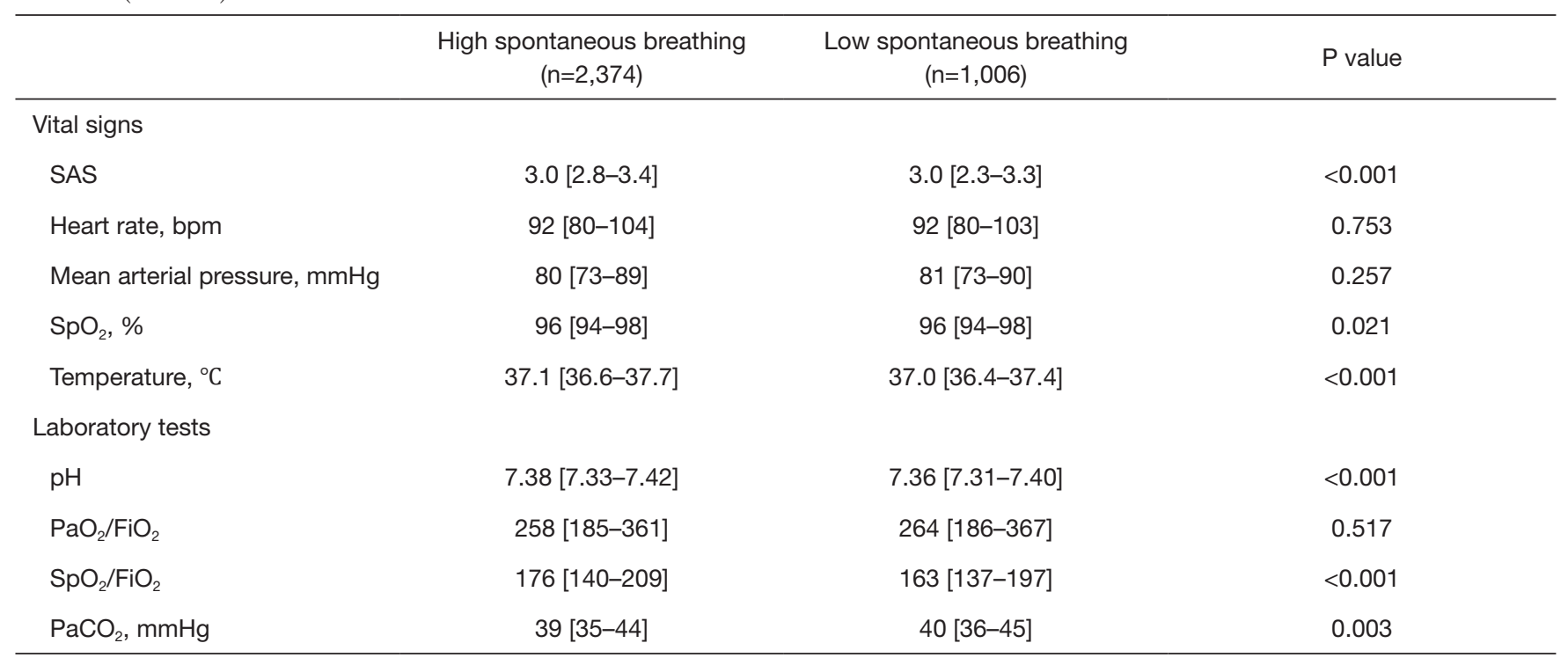

Data are median [quartile 25\%-quartile 75\%] or No. (\%). BMI, body mass index; PBW, predicted body weight; COPD, chronic obstructive pulmonary disease; ARDS, acute respiratory distress syndrome; SAPS, Simplified Acute Physiology Score; OASIS, Oxford Acute Severity of IIIness Score; SOFA, Sequential Organ Failure Assessment; bpm, beats per minute.

with neurological or neuromuscular disease). Also, the analysis leverages the availability of time-stamped vital signs, laboratory test results, and ventilatory parameters. This is the first clinical study addressing spontaneous breathing during mechanical ventilation in critically ill patients with this level of resolution and granularity of the data. Instead of defining the type of ventilation according to one single assessment per day, as in the majority of the studies (9), in the present investigation, this was assessed for every 6 hour-time windows, increasing the power of the study and avoiding surveillance bias. Also, the 48-hour time-interval inclusion criterion guaranteed that all patients were exposed to mechanical ventilation for a sufficient period of time. Finally, all results considered the effect of time using mixed-effect models with year of admission in the ICU as random effect. Indeed, this is important since distinct ventilation practices were applied over time.

The finding of this investigation mirror, at least in part, the analysis of the LUNG SAFE study (9) that showed spontaneous breathing to be associated with shorter duration of mechanical ventilation and ICU length stay in patients with ARDS. Our findings are also in agreement with results from studies of airway pressure release ventilation (APRV), a ventilation mode that allows spontaneous breathing, on patients with ARDS (3). Indeed, use of APRV was associated with shorter duration of ventilation and ICU length of stay. However, bias may have been introduced in these analyses, since spontaneous breathing was used more often in less sick patients.

In previous observational studies, bias may have been introduced in the analysis from confounding by indication, since spontaneous breathing is usually used more often in less sick patients. In addition, the classification of patients was based on one single observation point per each ventilation day (9). Of note, confounding by indication may not have been fully addressed by our analysis despite adjustment. But categorizing patients according to presence of spontaneous breathing at eight time-frames in the first 48 hours, surveillance bias was mitigated, at least more than in previous studies.

The potential benefits of the use of spontaneous breathing in patients receiving mechanical ventilation should be interpreted with caution. First, ventilator dyssynchronies are common, and its occurrence could increase with spontaneous breathing, and are associated with worse outcomes $(18,19)$. Also, previous studies in ARDS patients suggest that the effect of spontaneous breathing depends on the etiology and severity, with risk of harm proportional to ARDS severity $(9,20,21)$. An appropriate assessment of respiratory drive and inspiratory efforts is important when assessing the potential benefits of spontaneous breathing, and should be encouraged at 

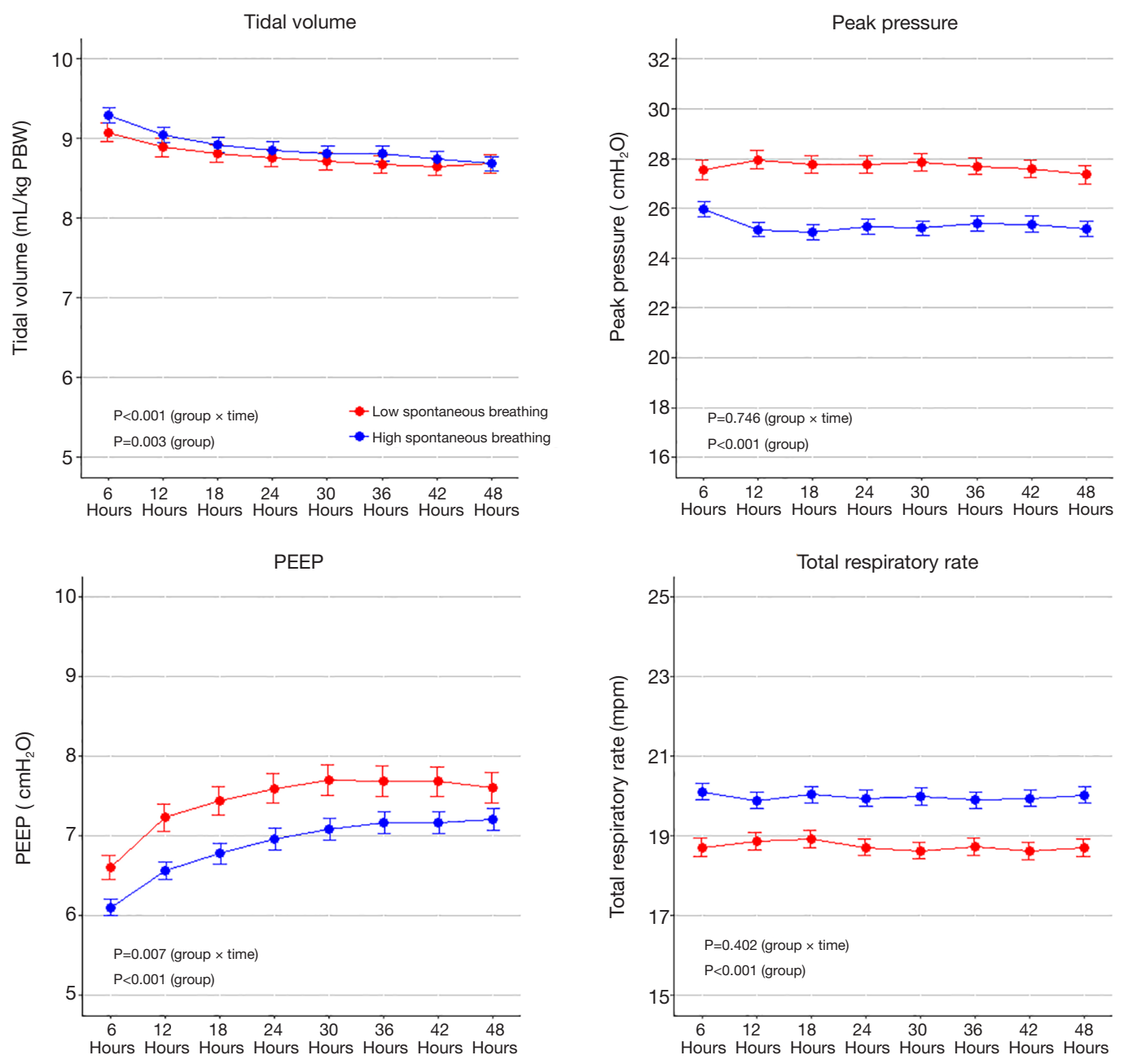

Figure 1 Measurements of ventilatory parameters every 6 hours for the first 48 hours of ventilation. Circles and bars are mean and $95 \%$ confidence interval. Mixed-effect longitudinal models with random intercept for patients and with group, time and the interaction of group $\times$ time as fixed effects. $\mathrm{P}$ values for the group reflect the overall test for difference between groups across the 48 hours while $\mathrm{P}$ values for the group $\times$ time interaction evaluate if change over time differed by group.

bedside (10). Measurements like airway occluding pressures, esophageal manometry, diaphragm electrical activity and even occlusion holds during PSV, are optimal to determine if harm arises from the spontaneous breaths (22-25). It is important to emphasize that in the present study the presence of inspiratory effort was not assessed and the presence of spontaneous activity was based in the mode of ventilation and respiratory rate. However, to the date this is a widely used approach to detect spontaneous breathing in observational studies $(9,26,27)$.

In the present analysis, the $\mathrm{V}_{\mathrm{T}}$ size was similar in patients with 'high spontaneous breathing' and those with 'low spontaneous breathing'. However, plateau and peak pressure, and PEEP were significantly lower in the group with 'high spontaneous breathing'. It is important to note that patients in the 'high spontaneous breathing' were more often ventilated with PSV, thus, the lower peak pressure can be due to the ventilatory mode and not only due to other respiratory factors, like the severity of the disease. The finding of a similar $V_{T}$ size between the two groups is important, since a large $\mathrm{V}_{\mathrm{T}}$ during spontaneous breathing may indicate a high inspiratory effort potentially increasing lung injury (9). However, in the presence of lower airway pressures, as in this analysis, even a larger $\mathrm{V}_{\mathrm{T}}$ size may be acceptable when there are no other signs of increased inspiratory efforts, since it may just represent a more 
Table 2 Ventilatory characteristics of the patients included

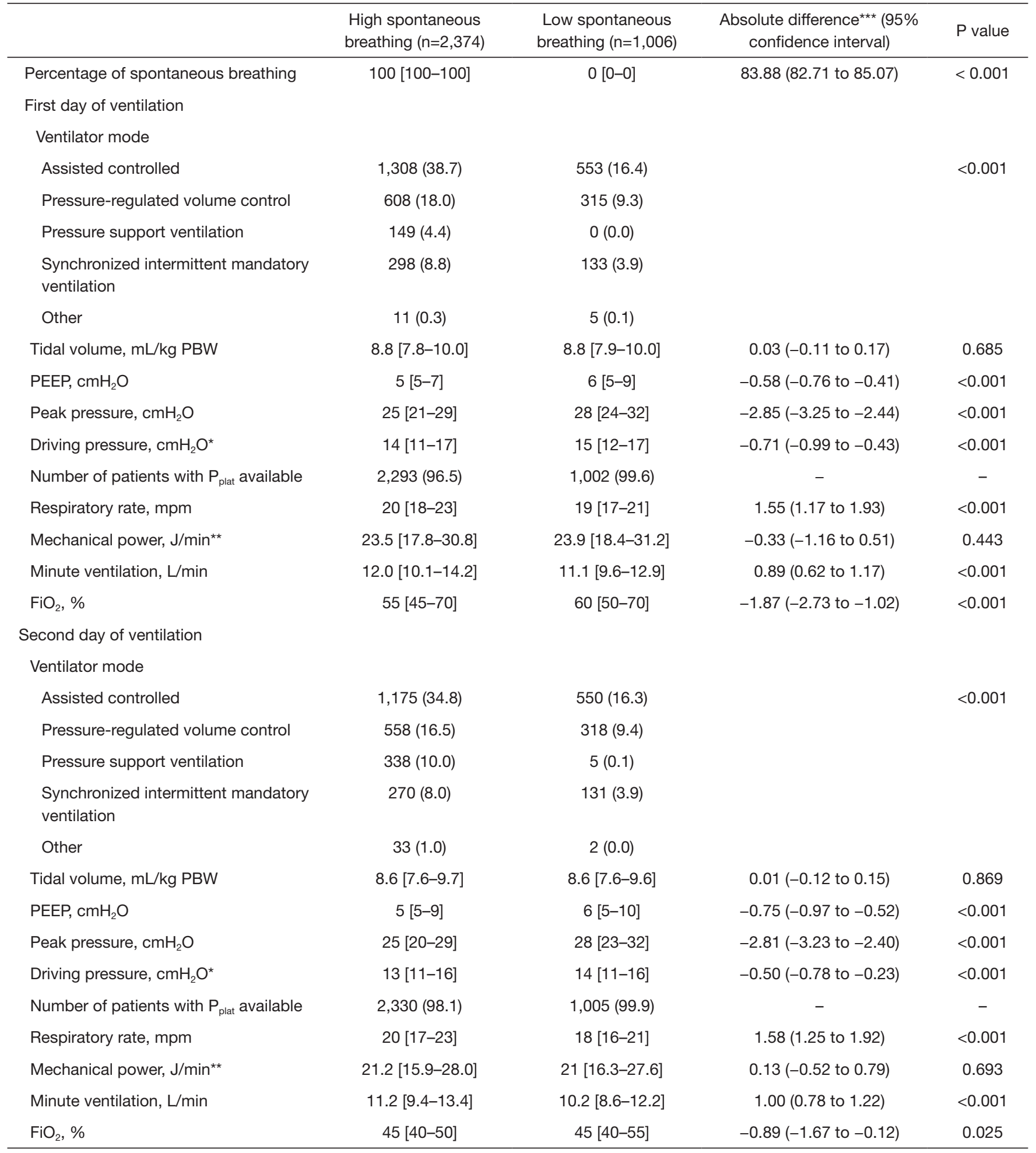

Data are median [quartile 25\%-quartile 75\%]. *calculated when plateau pressure is available and as plateau pressure - PEEP; ${ }^{* *}$ calculated when plateau pressure is available and as: $0.098 \times$ tidal volume $\times$ respiratory rate $\times$ (peak pressure - driving pressure/2); ${ }^{* \star *}$ mean difference from a univariable mixed-effect linear model with year as random effect. PEEP, positive end-expiratory pressure; $\mathrm{FiO}_{2}$, inspired fraction of oxygen. 
Table 3 Adjusted analyses for the primary and secondary outcomes

\begin{tabular}{|c|c|c|c|c|}
\hline & $\begin{array}{l}\text { High spontaneous breathing } \\
\qquad(\mathrm{n}=2,374)\end{array}$ & $\begin{array}{l}\text { Low spontaneous breathing } \\
\qquad(\mathrm{n}=1,006)\end{array}$ & $\begin{array}{l}\text { Absolute difference }{ }^{*, * *}(95 \% \\
\text { confidence interval) }\end{array}$ & $P$ value \\
\hline Ventilator-free days at day 28 & $20.0(0.0-24.2)$ & $19.0(0.00-23.7)$ & $0.54(-0.10 \text { to } 1.19)^{a}$ & 0.101 \\
\hline ICU length of stay, days & $9.5(5.8-15.7)$ & $10.0(6.0-17.1)$ & $-0.67(-1.49 \text { to } 0.15)^{\mathrm{a}}$ & 0.110 \\
\hline ICU mortality & $598(25.2)$ & $246(24.5)$ & $-0.43(-3.09 \text { to } 2.23)^{b}$ & 0.751 \\
\hline Hospital mortality & $712(30.0)$ & $281(27.9)$ & $-0.17(-2.85 \text { to } 2.49)^{b}$ & 0.903 \\
\hline 30-day mortality & $696(29.3)$ & $280(27.8)$ & $-0.38(-3.10 \text { to } 2.33)^{b}$ & 0.786 \\
\hline
\end{tabular}

Data are median (quartile $25 \%$-quartile $75 \%$ ) or No. (\%). *absolute difference from a multivariable mixed = effect linear model with year as random effect and adjusted for: age, gender, weight, initial diagnosis, Elixhauser comorbidity score, use of vasopressor in the first day, limitation of support, SAPS II, OASIS, SOFA at day 1 , heart rate at day 1 and 2 , mean arterial pressure at day 1 and 2 , and $\mathrm{SpO}_{2} / \mathrm{FiO}_{2}$ at day 1 and $2 .{ }^{* *}$ continuous variables were standardized before inclusion to improve convergence. ${ }^{a}$ effect estimate is mean difference; beffect estimate is risk ratio. ICU, intensive care unit.

compliant respiratory system (28).

\section{Limitations}

The observational retrospective nature of the study should be considered when interpreting the findings. Residual confounding is always a concern despite appropriate modeling and sensitivity analyses. The data was extracted from a singlecenter which may limit generalizability. Only patients who survived and received invasive ventilation for at least 48 hours were included, aiming to select more severely ill patients and also those who had been exposed to the primary exposure of interest for a sufficient period of time. However, the results cannot be applied to patients who were extubated or died within 48 hours of ICU admission. Total RR was compared with set RR to determine whether patients had spontaneous breathing. Nevertheless, it cannot be ascertained that patients whose total and set rate did not have spontaneous breathing. Also, the exposure assessed was dependent on the patient clinical condition over time, and this should be considered when interpreting the results. In addition, since the dataset used in this study is for clinical purposes and the present analysis is a secondary analysis of these data, we cannot guarantee that plateau pressure and other ventilatory variables were collected under standard conditions. Finally, the observation that patients with no spontaneous breathing were sicker may reflect a systematic bias toward the use of controlled ventilation in patients with higher severity.

\section{Conclusions}

In conclusion, in this analysis of a large ICU dataset of high resolution, in critically ill patients surviving and receiving ventilation for at least 48 hours, the amount of spontaneous breathing during this period was not associated with an increased number of ventilator-free days at day 28. This finding was not different for the various subgroups However, the amount of spontaneous breathing was associated with duration of mechanical ventilation among survivors, and the number of ventilator-free days at day 28 was higher in 'always spontaneous breathing' patients compared to 'never spontaneous breathing' patients.

\section{Acknowledgments}

Funding: Local funding was provided for the investigators by theirs centers. LAC is funded by the National Institute of Health through NIBIB R01 EB017205.

\section{Footnote}

Reporting Checklist: The authors have completed the STROBE reporting checklist. Available at http://dx.doi. org/10.21037/atm-20-7901

Peer Review File: Available at http://dx.doi.org/10.21037/ atm-20-7901 
Data Sharing Statement: Available at http://dx.doi. org/10.21037/atm-20-7901

Conflicts of Interest: All authors have completed the ICMJE uniform disclosure form (available at http:// dx.doi.org/10.21037/atm-20-7901). Dr. MGdA reports grants and personal fees from Drager, grants and personal fees from GlaxoSmithKline, personal fees from GE Healthcare, outside the submitted work. Dr. ASN reports personal fees from Drager, outside the submitted work. The other authors have no conflicts of interest to declare.

Ethical Statement: The authors are accountable for all aspects of the work in ensuring that questions related to the accuracy or integrity of any part of the work are appropriately investigated and resolved. The study was conducted in accordance with the Declaration of Helsinki (as revised in 2013). The study was approved by the Institutional Review Board of the Beth Israel Deaconess Medical Center (2001-P-001699/14) and the Massachusetts Institute of Technology (No. 0403000206) and individual consent for this retrospective analysis was waived.

Open Access Statement: This is an Open Access article distributed in accordance with the Creative Commons Attribution-NonCommercial-NoDerivs 4.0 International License (CC BY-NC-ND 4.0), which permits the noncommercial replication and distribution of the article with the strict proviso that no changes or edits are made and the original work is properly cited (including links to both the formal publication through the relevant DOI and the license). See: https://creativecommons.org/licenses/by-nc-nd/4.0/.

\section{References}

1. Jaber S, Petrof BJ, Jung B, et al. Rapidly progressive diaphragmatic weakness and injury during mechanical ventilation in humans. Am J Respir Crit Care Med 2011;183:364-71.

2. Futier E, Constantin JM, Combaret L, et al. Pressure support ventilation attenuates ventilator-induced protein modifications in the diaphragm. Crit Care 2008;12:R116.

3. Putensen C, Zech S, Wrigge H, et al. Long-term effects of spontaneous breathing during ventilatory support in patients with acute lung injury. Am J Respir Crit Care Med 2001;164:43-9.

4. Neto AS, Barbas CSV, Simonis FD, et al. Epidemiological characteristics, practice of ventilation, and clinical outcome in patients at risk of acute respiratory distress syndrome in intensive care units from 16 countries (PRoVENT): an international, multicentre, prospective study. Lancet Respir Med 2016;4:882-93.

5. Gajic O, Dara SI, Mendez JL, et al. Ventilator-associated lung injury in patients without acute lung injury at the onset of mechanical ventilation. Crit Care Med 2004:32:1817-24.

6. Slutsky AS, Ranieri VM. Ventilator-induced lung injury. N Engl J Med 2013;369:2126-36.

7. Levine S, Nguyen T, Taylor N, et al. Rapid disuse atrophy of diaphragm fibers in mechanically ventilated humans. $\mathrm{N}$ Engl J Med 2008;358:1327-35.

8. Yoshida T, Rinka H, Kaji A, et al. The impact of spontaneous ventilation on distribution of lung aeration in patients with acute respiratory distress syndrome: airway pressure release ventilation versus pressure support ventilation. Anesth Analg 2009;109:1892-900.

9. Haren FV, Pham T, Brochard L, et al. Spontaneous Breathing in Early Acute Respiratory Distress Syndrome: Insights from the Large observational study to UNderstand the Global Impact of Severe Acute Respiratory FailurE Study*. Crit Care Med 2019;47:229-38.

10. Telias I, Brochard L, Goligher EC. Is my patient's respiratory drive (too) high? Intensive Care Med 2018;44:1936-9.

11. Johnson AEW, Pollard TJ, Shen L, et al. MIMICIII, a freely accessible critical care database. Sci Data 2016;3:160035.

12. Johnson AE, Stone DJ, Celi LA, et al. The MIMIC Code Repository: enabling reproducibility in critical care research. J Am Med Inform Assoc 2018;25:32-9.

13. Johnson AEW, Kramer A, Clifford GD. Computing in Cardiology Conference (CinC), 2014. Vol. 41. IEEE; 2014. Data preprocessing and mortality prediction: the Physionet/CinC 2012 challenge revisited; p. 157-60.

14. Cao H, Lee KP, Ennett CM, et al. Heuristics to determine ventilation times of ICU patients from the MIMICII database. Annu Int Conf IEEE Eng Med Biol Soc 2010;2010:5213-6.

15. Deden K. Ventilation modes in intensive care. Dräger.

16. Acute Respiratory Distress Syndrome Network, Brower RG, Matthay MA, et al. Ventilation with lower tidal volumes as compared with traditional tidal volumes for acute lung injury and the acute respiratory distress syndrome. N Engl J Med 2000;342:1301-8.

17. ARDS Definition Task Force, Ranieri VM, Rubenfeld GD, et al. Acute respiratory distress syndrome: the Berlin 
definition. JAMA 2012;307:2526-33.

18. Blanch L, Villagra A, Sales B, et al. Asynchronies during mechanical ventilation are associated with mortality. Intensive Care Med 2015;41:633-41.

19. Vaporidi K, Babalis D, Chytas A, et al. Clusters of ineffective efforts during mechanical ventilation: Impact on outcome. Intensive Care Med 2017;43:184-91.

20. Carvalho NC, Güldner A, Beda A, et al. Higher levels of spontaneous breathing reduce lung injury in experimental moderate acute respiratory distress syndrome. Crit Care Med 2014;42:e702-15.

21. Güldner A, Braune A, Carvalho N, et al: Higher levels of spontaneous breathing induce lung recruitment and reduce global stress/strain in experimental lung injury. Anesthesiology 2014;120:673-82.

22. Yoshida T, Amato MBP, Kavanagh BP. Understanding spontaneous vs. ventilator breaths: Impact and monitoring. Intensive Care Med 2018;44:2235-8.

23. Bellani G, Grassi A, Sosio S, et al. Driving Pressure Is Associated with Outcome during Assisted Ventilation in Acute Respiratory Distress Syndrome. Anesthesiology

Cite this article as: Reis AMD, Midega TD, Deliberato RO, Johnson AEW, Bulgarelli L, Correa TD, Celi LA, Pelosi P, Gama de Abreu M, Schultz MJ, Serpa Neto A; for the PROVE Network investigators. Effect of spontaneous breathing on ventilator-free days in critically ill patients-an analysis of patients in a large observational cohort. Ann Transl Med 2021;9(9):783. doi: 10.21037/atm-20-7901
2019;131:594-604.

24. Bertoni M, Telias I, Urner M, et al. A novel non-invasive method to detect excessively high respiratory effort and dynamic transpulmonary driving pressure during mechanical ventilation. Crit Care 2019;23:346.

25. Telias I, Junhasavasdikul D, Rittayamai N, et al. Airway Occlusion Pressure as an Estimate of Respiratory Drive and Inspiratory Effort During Assisted Ventilation. Am J Respir Crit Care Med 2020;201:1086-98.

26. Bellani G, Laffey JG, Pham T, et al. Epidemiology, Patterns of Care, and Mortality for Patients With Acute Respiratory Distress Syndrome in Intensive Care Units in 50 Countries. JAMA 2016;315:788-800.

27. Amato MB, Meade MO, Slutsky AS, et al. Driving pressure and survival in the acute respiratory distress syndrome. $\mathrm{N}$ Engl J Med 2015;372:747-55.

28. Georgopoulos D, Xirouchaki N, Tzanakis N, et al. Driving pressure during assisted mechanical ventilation: Is it controlled by patient brain? Respir Physiol Neurobiol 2016;228:69-75. 


\section{Additional methods}

\section{Characteristics of the study dataset}

The data were prospectively collected and stored in two different databases. The Medical Information Mart for Intensive Care III database (MIMIC-III v1.4), is a freely accessible and conveniently-sized database that contains high resolution information from hospital monitoring systems (including laboratory data, medication, and hospital administrative data) and bedside monitoring systems (vital signs, caregivers notes, radiology reports). This database is hosted by the Laboratory for Computational Physiology at the Massachusetts Institute of Technology (MIT) and contains data for over 50,000 de-identified patient admissions to ICUs at the BIDMC from 2001 to 2012. We used the MIMIC Code Repository to define many concepts in MIMIC-III.

\section{Ethical approval}

The Institutional Review Board of the Beth Israel Deaconess Medical Center (2001-P-001699/14) and the Massachusetts Institute of Technology (No. 0403000206) approved use of the MIMIC database.

\section{Statistical analyses}

Relevant covariates known to predict outcome were entered into the multivariable model if a $p$ value less than 0.1 was found in the univariable model and when the percentage of missing was less than $10 \%$. In the adjusted models for the comparison of the groups (high vs. low spontaneous breathing and always $v s$. never spontaneous breathing), relevant covariates known to predict outcome were included, not considering variables with more than $10 \%$ of missing. In addition, ventilatory variables were not included in the model, since they are closely related to the types of ventilation studied and could mediate the relationship between them and outcomes. At the end, the following variables were considered: age, gender, weight, initial diagnosis, Elixhauser comorbidity score, use of vasopressor in the first day, limitation of support, SAPS II, OASIS, SOFA at day 1 , heart rate at day 1 and 2, mean arterial pressure at day 1 and 2, and $\mathrm{SpO}_{2} / \mathrm{FiO}_{2}$ at day 1 and 2. All continuous variables were standardized before inclusion in the models to improve convergence. The use of neuromuscular blocking agents was not considered in the models due to its highly correlation with the variable of interest (spontaneous breathing). 
Table S1 Classification of ventilation modes in the MIMIC-III dataset

\begin{tabular}{|c|c|c|}
\hline Original Classification & Re-classification & $\begin{array}{l}\text { Mode Mandating } \\
\text { Spontaneous Breathing }\end{array}$ \\
\hline APRV & Airway Pressure Release Ventilation (APRV) & No \\
\hline Assist Control & Assist Control & No \\
\hline CMV & Continuous Mandatory Ventilation & No \\
\hline CMV/ASSIST/AutoFlow & Pressure Regulated Volume Control (PRVC) & No \\
\hline CMV/AutoFlow & Pressure Regulated Volume Control (PRVC) & No \\
\hline CPAP & Continuous Positive Airway Pressure (CPAP) & Yes \\
\hline CPAP/PPS & Proportional Assist Ventilation (PAV) & Yes \\
\hline CPAP/PSV+ApnVol & Pressure Support Ventilation (PSV) & Yes \\
\hline $\mathrm{CPAP}+\mathrm{PS}$ & Pressure Support Ventilation (PSV) & Yes \\
\hline MMV & Mandatory Minute Ventilation (MMV) & No \\
\hline MMV/AutoFlow & Mandatory Minute Ventilation (MMV) & No \\
\hline MMV/PSV & Mandatory Minute Ventilation-PSV (MMV-PSV) & No \\
\hline MMV/PSV/AutoFlow & Mandatory Minute Ventilation-PSV (MMV-PSV) & No \\
\hline Other/Remarks & Other & No \\
\hline $\mathrm{PCV}+$ & Pressure Control & No \\
\hline PRVC/AC & Pressure Regulated Volume Control (PRVC) & No \\
\hline PSV/SBT & Pressure Support Ventilation (PSV) & Yes \\
\hline SIMV & Synchronized Intermittent Mandatory Ventilation (SIMV) & No \\
\hline SIMV/AutoFlow & Synchronized Intermittent Mandatory Ventilation (SIMV) & No \\
\hline SIMV/PSV & Synchronized Intermittent Mandatory Ventilation (SIMV) & No \\
\hline SIMV/PSV/AutoFlow & Synchronized Intermittent Mandatory Ventilation (SIMV) & No \\
\hline SIMV+PS & Synchronized Intermittent Mandatory Ventilation (SIMV) & No \\
\hline Standby & Other & No \\
\hline SYNCHRON MASTER & Synchronized Intermittent Mandatory Ventilation (SIMV) & No \\
\hline SYNCHRON SLAVE & Synchronized Intermittent Mandatory Ventilation (SIMV) & No \\
\hline TCPCV & Pressure Control & No \\
\hline VOL/AC & Volume Control & No \\
\hline
\end{tabular}


Table S2 Example of how patients were categorized in the present study in the MIMIC-III when using an assist control mode

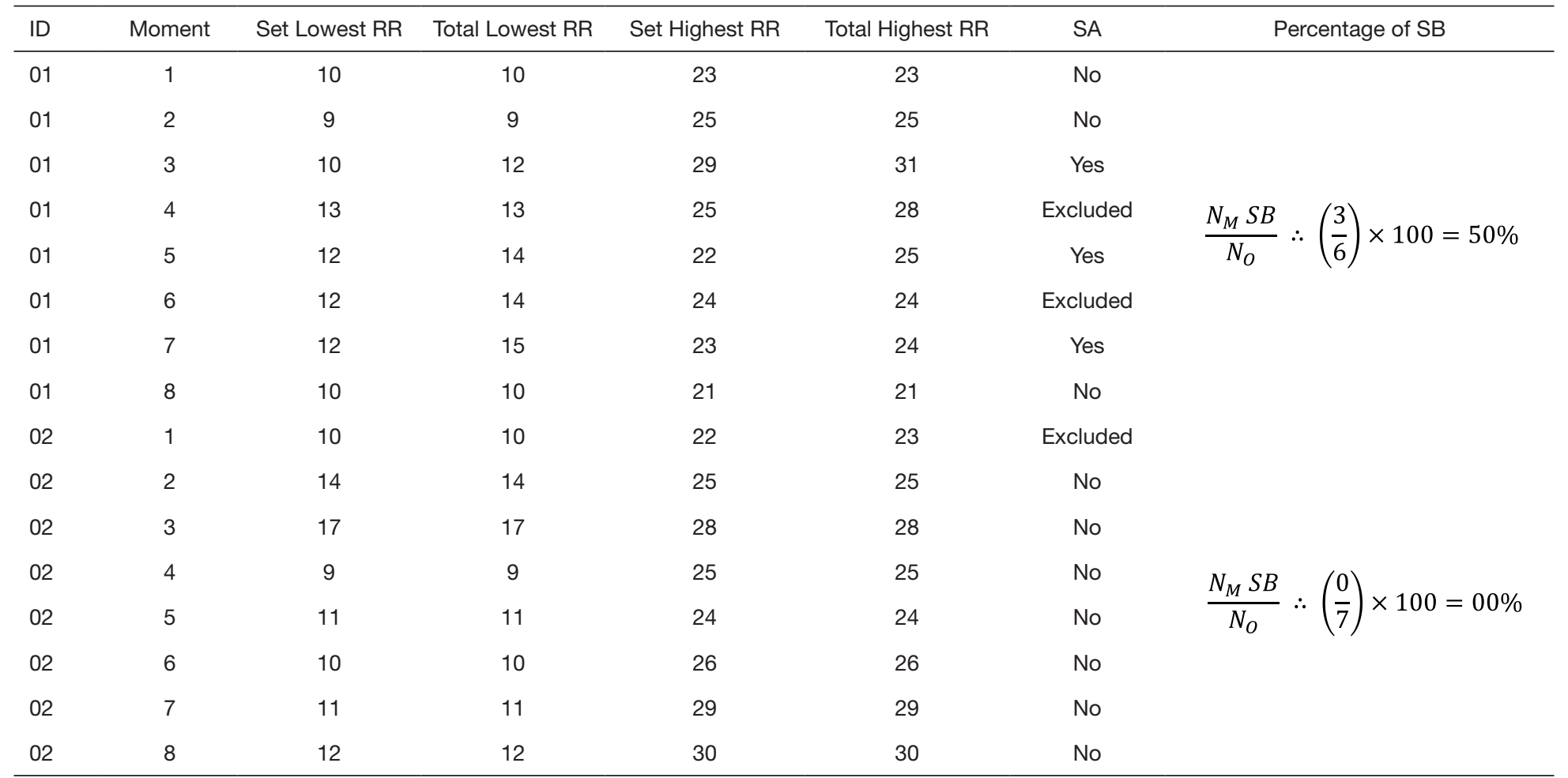

ID: unique identificator; RR: respiratory rate; $\mathrm{SB}$ : spontaneous breathing; $\mathrm{N}_{\mathrm{M}} \mathrm{SB}$ : number of moments with spontaneous breathing; $\mathrm{N}_{\mathrm{O}}$ : number of observations available. 


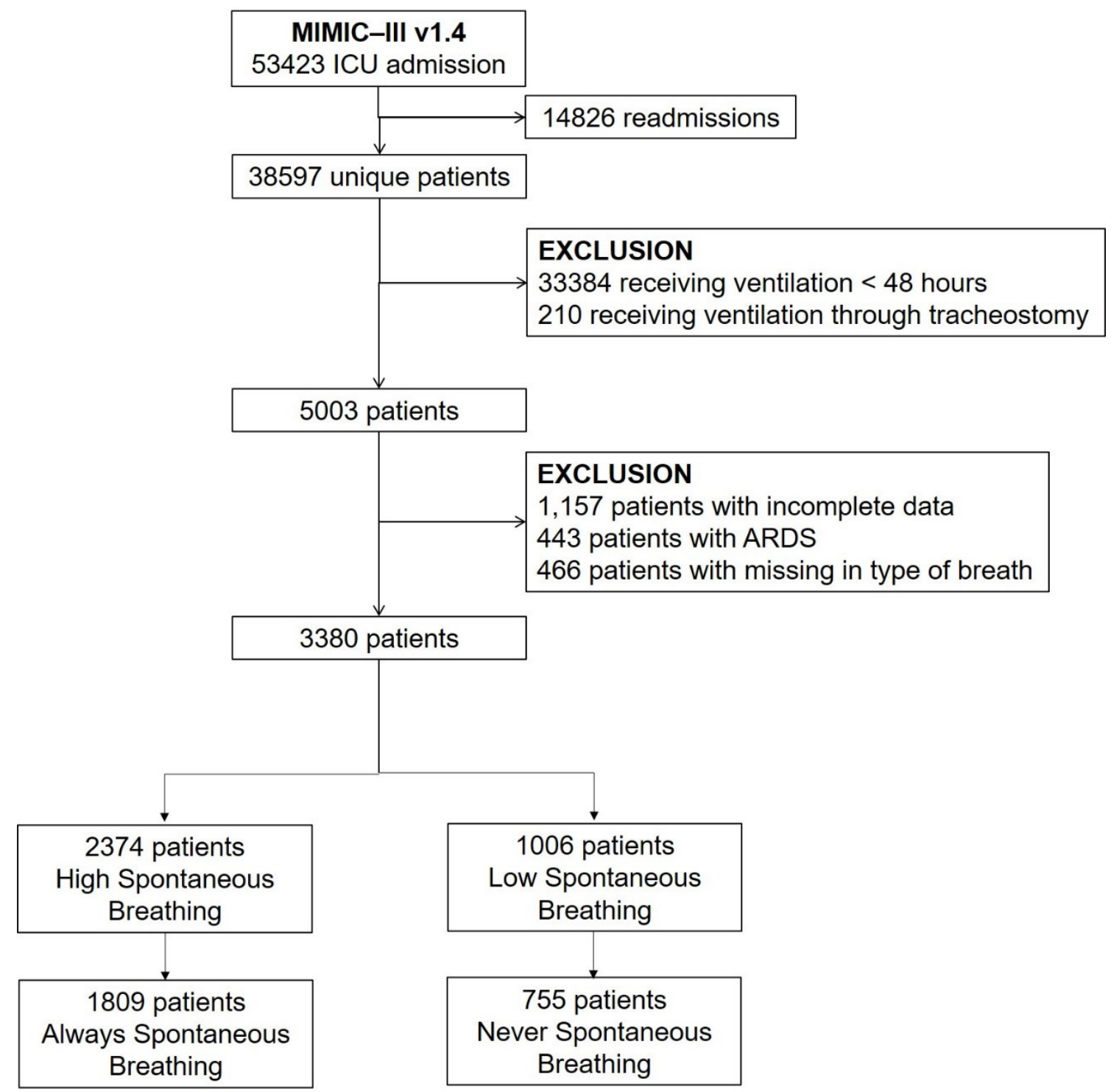

Figure S1 Flowchart of the study in the MIMIC-III dataset. 
Table S3 Vital signs and laboratory tests

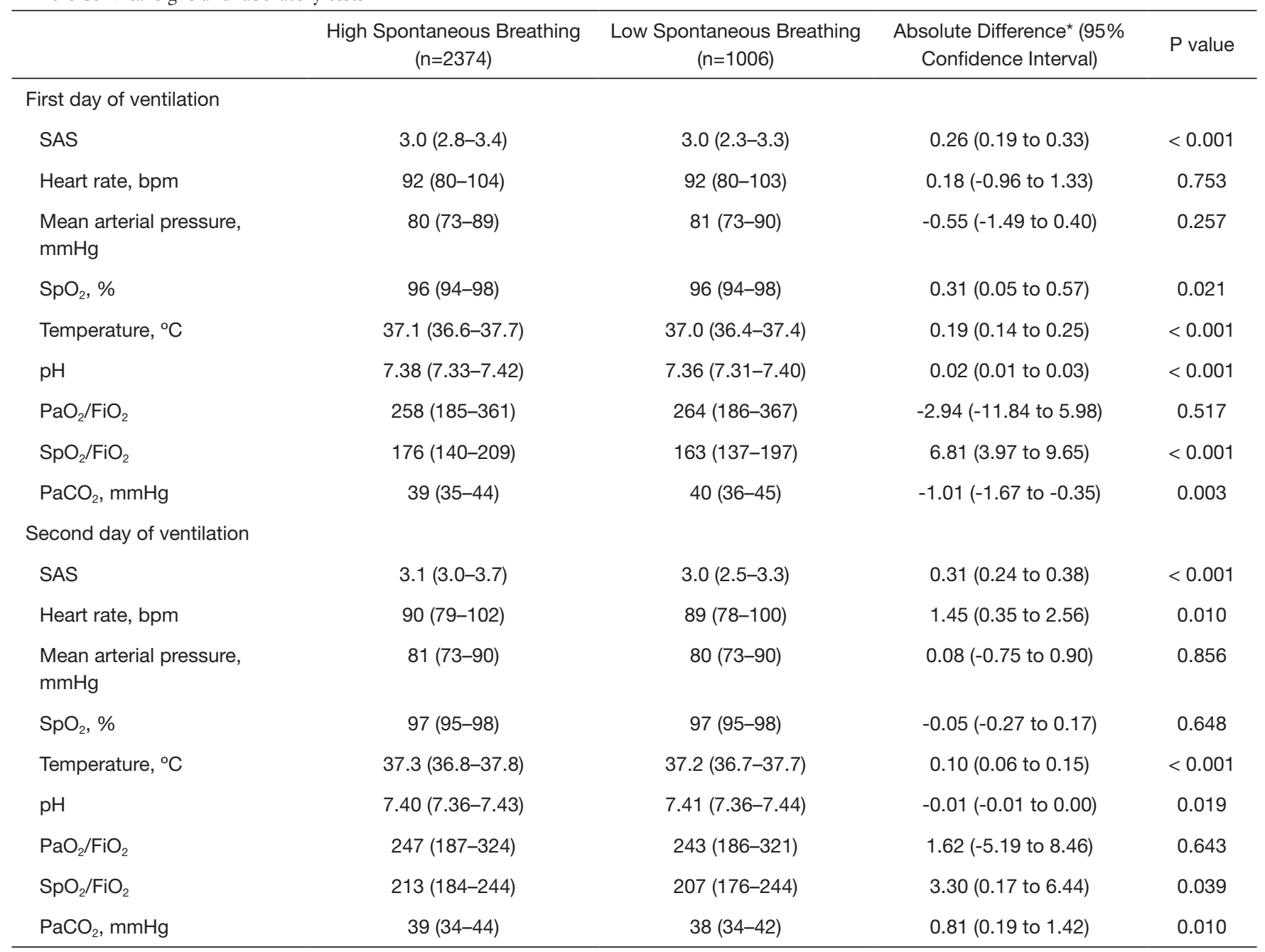

Data are median (quartile $25 \%$ - quartile $75 \%$ ). $\mathrm{SpO}_{2}$ : pulse oximetry; SAS: sedation agitation scale. ${ }^{*}$ mean difference from a univariable mixed-effect linear model with year as random effect. 


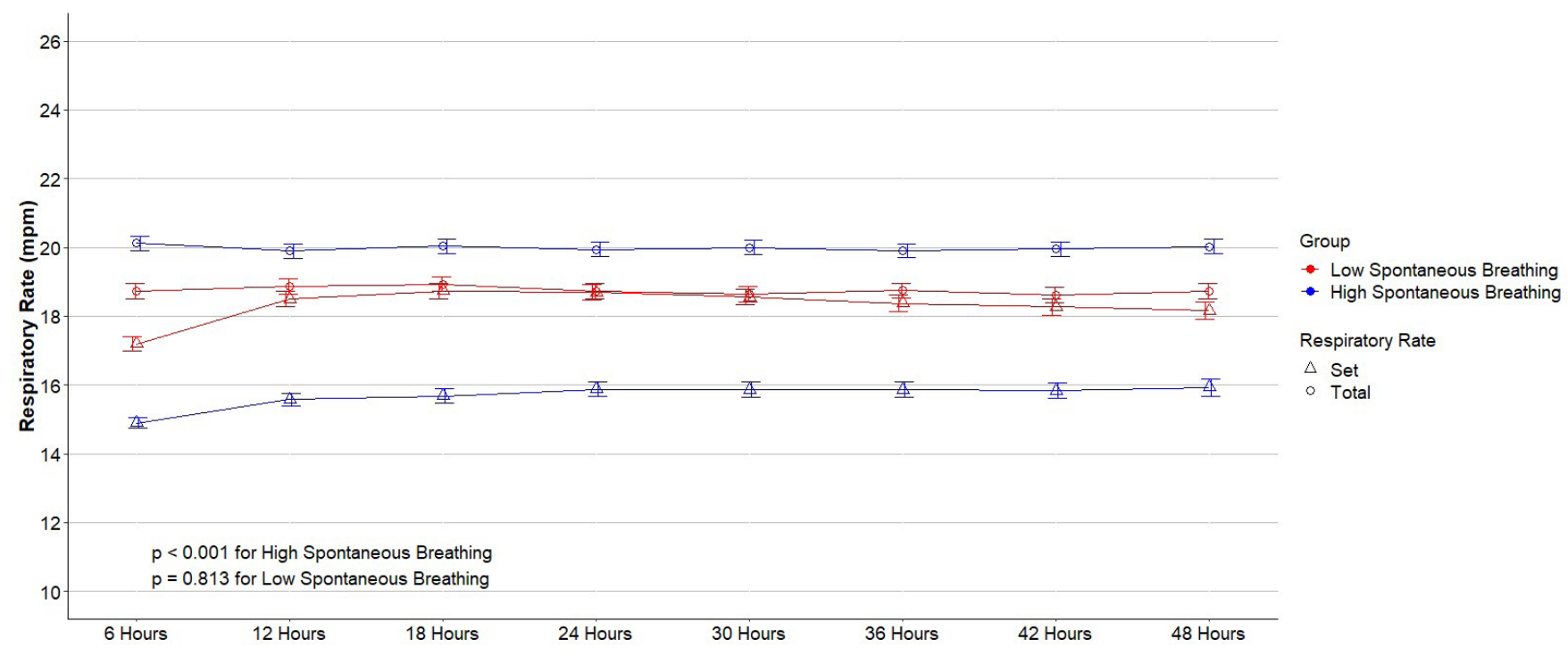

Figure S2 Comparison of set and total respiratory rate among groups. Symbols and bars are mean and 95\% confidence interval. Mixedeffect longitudinal models with random intercept for patients and year of admission, and with group, time and the interaction of group $\mathrm{x}$ time as fixed effects. $\mathrm{P}$ values reported are for the group and reflect the overall test for difference between groups across the 48 hours.

Table S4 Unadjusted analyses for the primary and secondary outcomes

\begin{tabular}{|c|c|c|c|c|}
\hline & $\begin{array}{l}\text { High Spontaneous Breathing } \\
\qquad(\mathrm{n}=2374)\end{array}$ & $\begin{array}{l}\text { Low Spontaneous Breathing } \\
\qquad(n=1006)\end{array}$ & $\begin{array}{l}\text { Absolute Difference* (95\% } \\
\text { Confidence Interval) }\end{array}$ & $P$ value \\
\hline Ventilator-free days at day 28 & $20.0(0.0-24.2)$ & $19.0(0.00-23.7)$ & $0.19(-0.59 \text { to } 0.97)^{\mathrm{a}}$ & 0.635 \\
\hline ICU length of stay, days & $9.5(5.8-15.7)$ & $10.0(6.0-17.1)$ & $-0.80(-1.57 \text { to }-0.02)^{a}$ & 0.043 \\
\hline ICU mortality & $598(25.2)$ & $246(24.5)$ & $0.74(-2.46 \text { to } 3.93)^{\mathrm{b}}$ & 0.651 \\
\hline Hospital mortality & $712(30.0)$ & $281(27.9)$ & $2.06(-1.30 \text { to } 5.42)^{b}$ & 0.230 \\
\hline 30-day mortality & $696(29.3)$ & $280(27.8)$ & $1.48(-1.86 \text { to } 4.83)^{\mathrm{b}}$ & 0.384 \\
\hline
\end{tabular}

Data are median (quartile $25 \%$ - quartile $75 \%$ ) or N (percentage). ICU: intensive care unit; *absolute difference from a univariable mixedeffect linear model with year as random effect; ${ }^{a}$ effect estimate is mean difference; ${ }^{b}$ effect estimate is risk ratio.

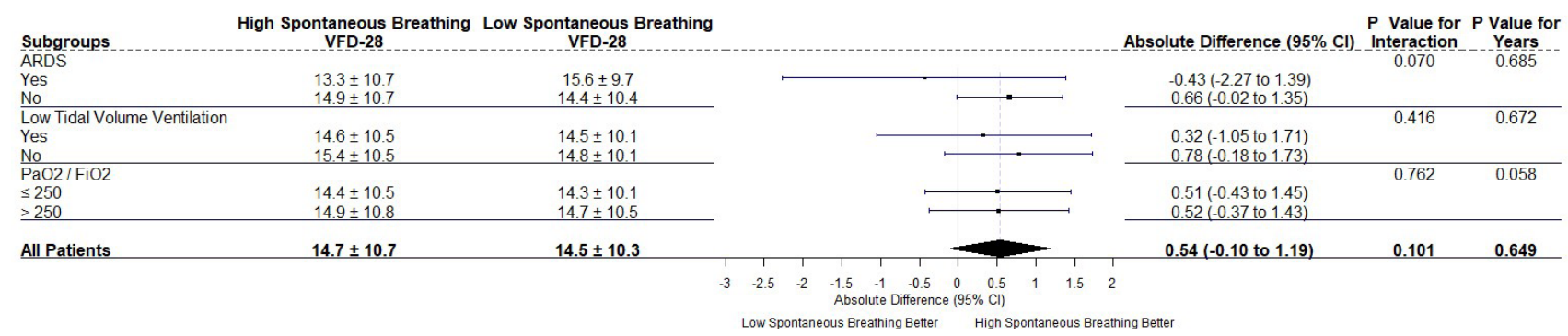

Figure S3 Subgroup analyses. 
Table S5 Baseline characteristics of the included patients according to more strict groups

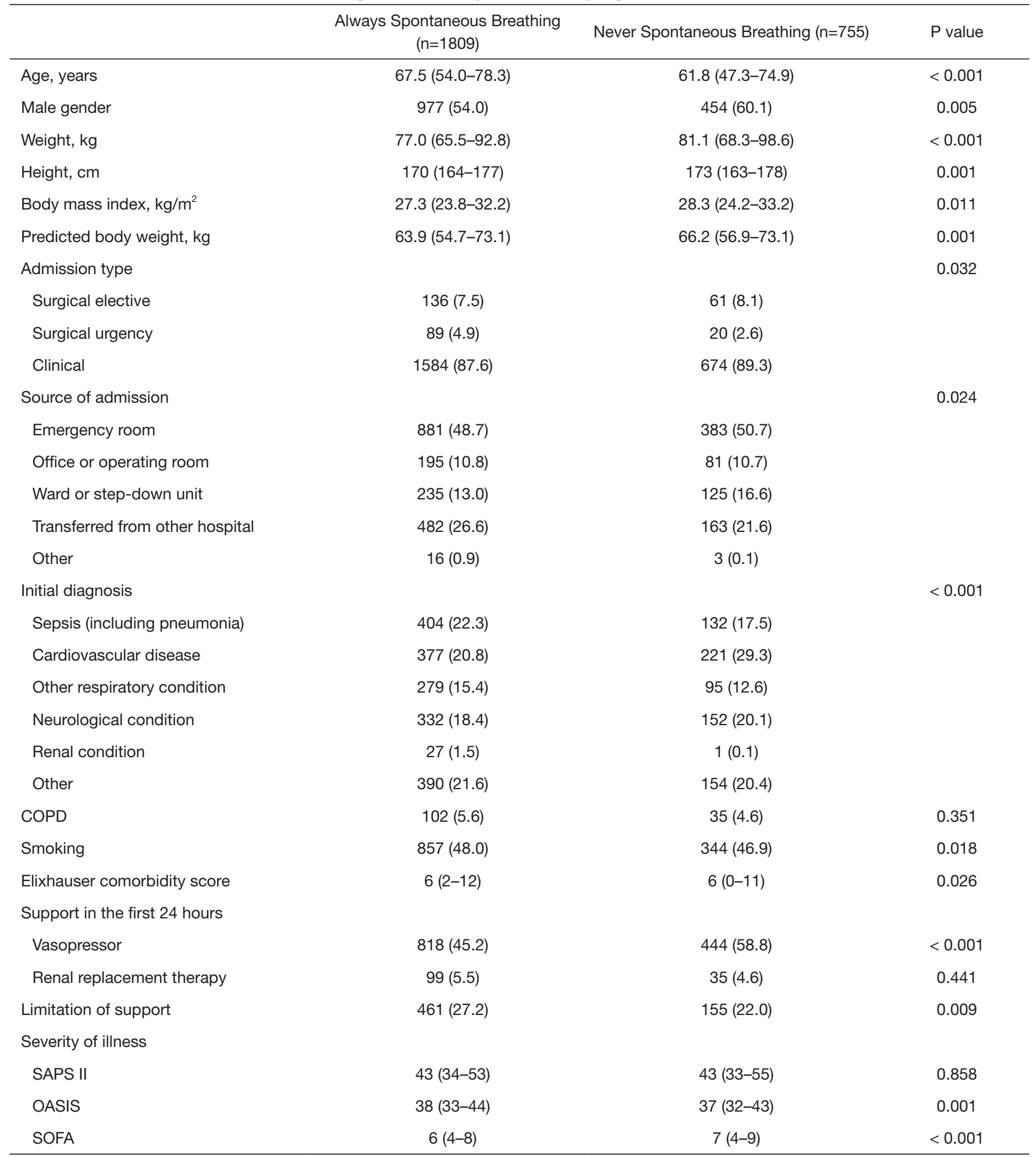

Data are median (quartile $25 \%$ - quartile $75 \%$ ) or No (\%). BMI: body mass index; PBW: predicted body weight; COPD: chronic obstructive pulmonary disease; ARDS: acute respiratory distress syndrome; SAPS: Simplified Acute Physiology Score; OASIS: Oxford Acute Severity of Illness Score; SOFA: Sequential Organ Failure Assessment; bpm: beats per minute. 
Table S6 Vital signs and laboratory tests according to more strict groups

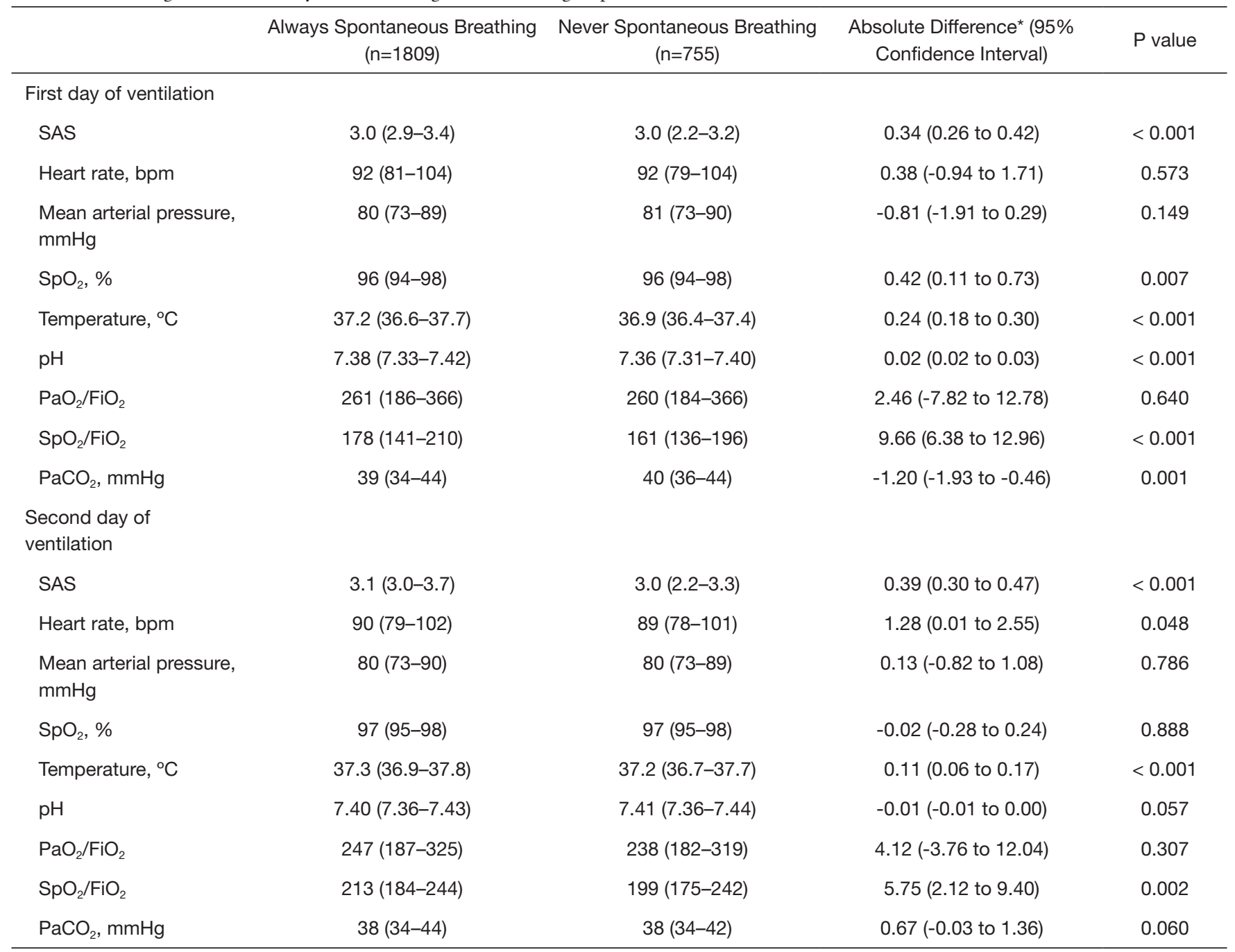

Data are median (quartile $25 \%$ - quartile $75 \%$ ). $\mathrm{SpO}_{2}$ : pulse oximetry; SAS: sedation agitation scale; ${ }^{*}$ mean difference from a univariable mixed-effect linear model with year as random effect. 
Table S7 Ventilatory characteristics of the patients included according to more strict groups

\begin{tabular}{|c|c|c|c|c|}
\hline & $\begin{array}{l}\text { Always Spontaneous Breathing } \\
\qquad(\mathrm{n}=1809)\end{array}$ & $\begin{array}{l}\text { Never Spontaneous } \\
\text { Breathing }(n=755)\end{array}$ & $\begin{array}{l}\text { Absolute Difference }{ }^{\star * *}(95 \% \\
\text { Confidence Interval) }\end{array}$ & $P$ value \\
\hline $\begin{array}{l}\text { Percentage of spontaneous } \\
\text { breathing }\end{array}$ & $100(100-100)$ & $0(0-0)$ & - & - \\
\hline \multicolumn{5}{|l|}{ First day of ventilation } \\
\hline Tidal volume, $\mathrm{ml} / \mathrm{kg}$ PBW & $8.9(7.9-10.1)$ & $8.8(7.9-10.0)$ & $0.09(-0.07$ to 0.25$)$ & 0.249 \\
\hline Peak pressure, $\mathrm{cmH}_{2} \mathrm{O}$ & $24(20-29)$ & $28(24-33)$ & $-3.59(-4.06$ to -3.13$)$ & $<0.001$ \\
\hline Driving pressure, $\mathrm{cmH}_{2} \mathrm{O}^{*}$ & $14(11-17)$ & $15(12-17)$ & $-0.89(-1.22$ to -0.56$)$ & $<0.001$ \\
\hline Respiratory rate, mpm & $20(18-24)$ & $19(17-21)$ & 1.76 (1.35 to 2.17$)$ & $<0.001$ \\
\hline Mechanical power, J/min & $23.3(17.6-30.6)$ & $24.1(18.5-31.5)$ & $-0.85(-1.78$ to 0.09$)$ & 0.076 \\
\hline \multicolumn{5}{|l|}{ Second day of ventilation } \\
\hline Tidal volume, $\mathrm{ml} / \mathrm{kg}$ PBW & $8.7(7.6-9.8)$ & $8.6(7.6-9.6)$ & $0.03(-0.12$ to 0.19$)$ & 0.651 \\
\hline PEEP, $\mathrm{cmH}_{2} \mathrm{O}$ & $5(5-8)$ & $7(5-10)$ & $-1.07(-1.33$ to -0.81$)$ & $<0.001$ \\
\hline Peak pressure, $\mathrm{cmH}_{2} \mathrm{O}$ & $24(20-29)$ & $28(24-32)$ & $-3.48(-3.96$ to -3.00$)$ & $<0.001$ \\
\hline Driving pressure, $\mathrm{cmH}_{2} \mathrm{O}^{*}$ & $13(11-16)$ & $14(12-16)$ & $-0.63(-0.95$ to -0.32$)$ & $<0.001$ \\
\hline Respiratory rate, $\mathrm{mpm}$ & $20(17-23)$ & $18(15-21)$ & 1.71 (1.32 to 2.10$)$ & $<0.001$ \\
\hline Mechanical power, J/min ${ }^{* *}$ & $21.0(15.7-27.8)$ & $21.6(16.5-27.9)$ & $-0.38(-1.14$ to 0.38$)$ & 0.325 \\
\hline
\end{tabular}

Data are median (quartile $25 \%$ - quartile $75 \%$ ). PEEP: positive end-expiratory pressure; $\mathrm{FiO}_{2}$ : inspired fraction of oxygen; * calculated when plateau pressure is available and as plateau pressure - PEEP; ${ }^{* *}$ calculated when plateau pressure is available and as: $0.098 \times$ tidal volume $\times$ respiratory rate $\times\left(\right.$ peak pressure - driving pressure/2); ${ }^{\star \star *}$ mean difference from a univariable mixed-effect linear model with year as random effect. 


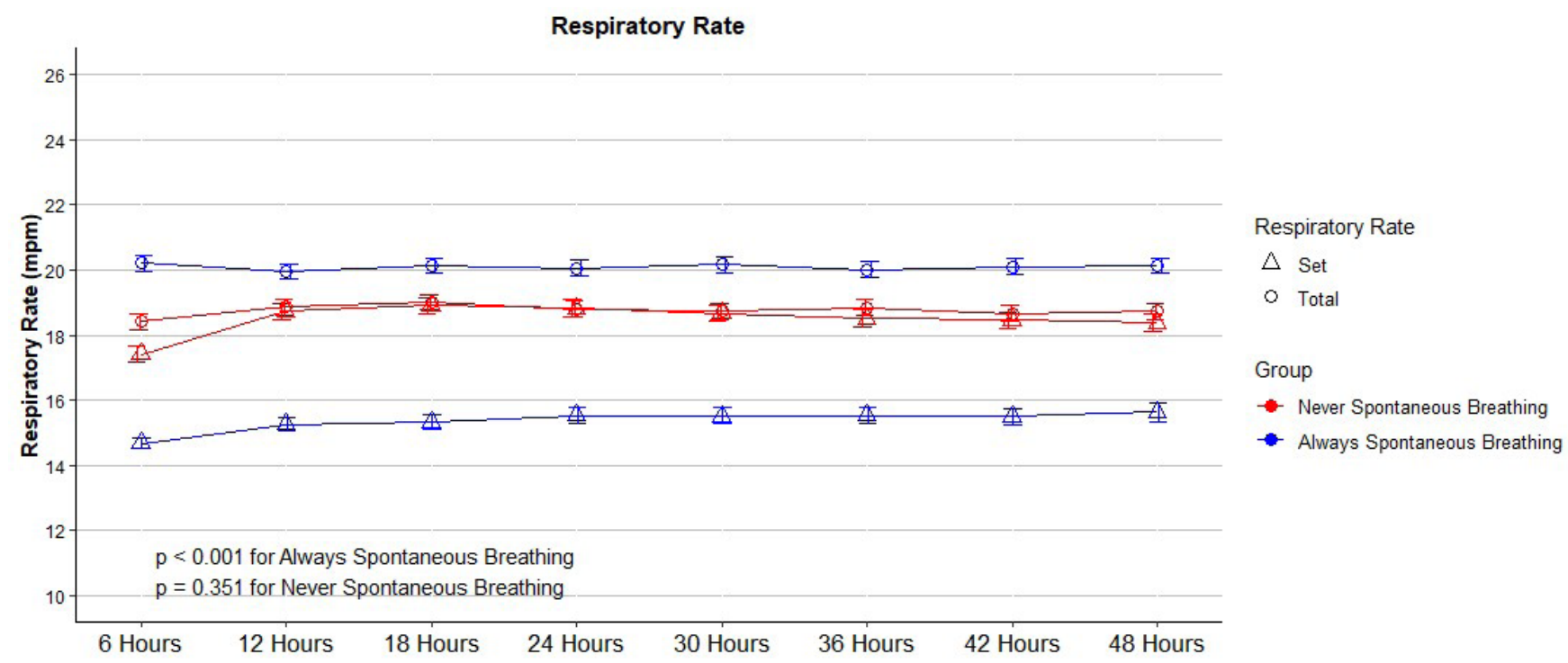

Figure $\mathbf{S 4}$ omparison of set and total respiratory rate among more strict groups Symbols and bars are mean and $95 \%$ confidence interval. Mixed-effect longitudinal models with random intercept for patients and year of admission, and with group, time and the interaction of group $\mathrm{x}$ time as fixed effects. $\mathrm{P}$ values reported are for the group and reflect the overall test for difference between groups across the 48 hours. 
Tidal Volume

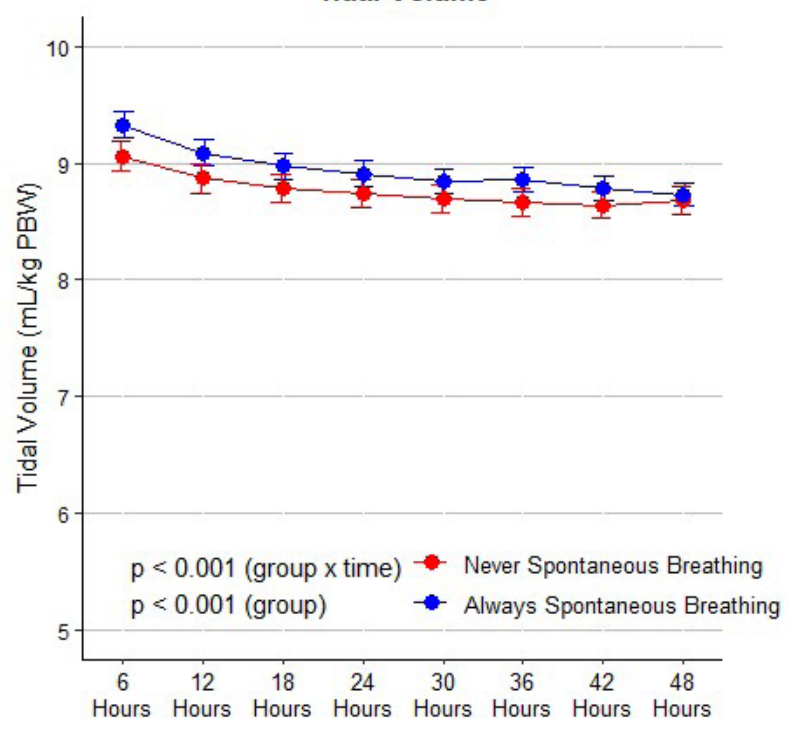

PEEP

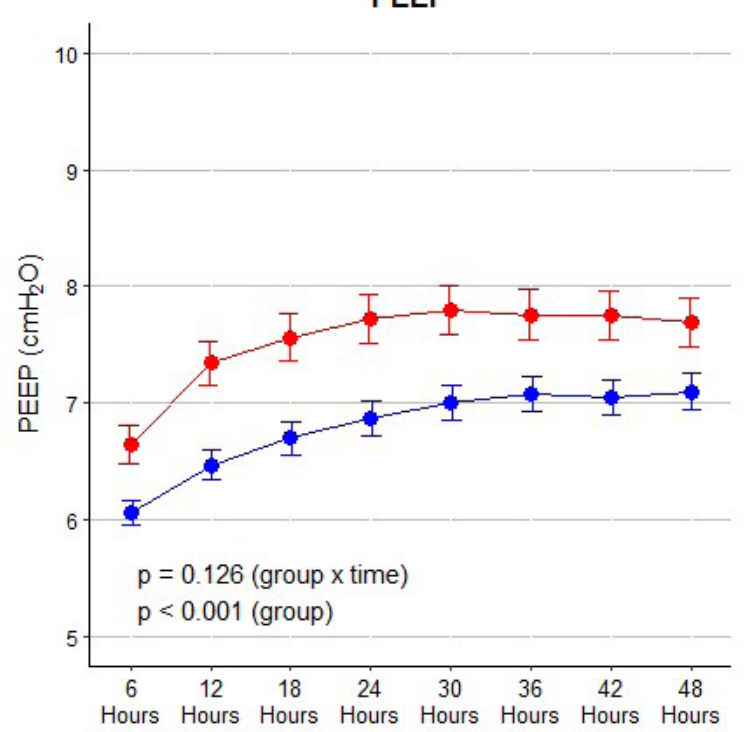

Peak Pressure

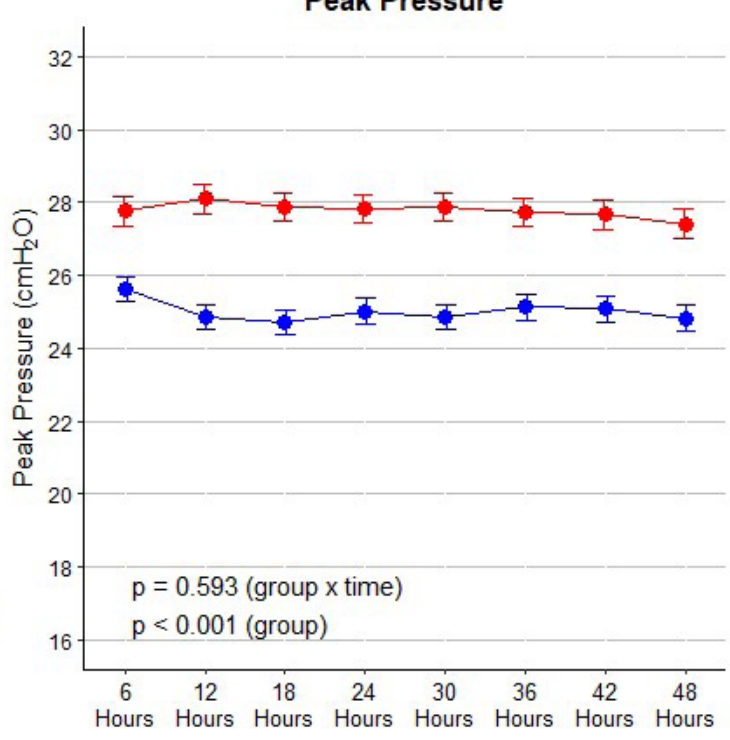

Total Respiratory Rate

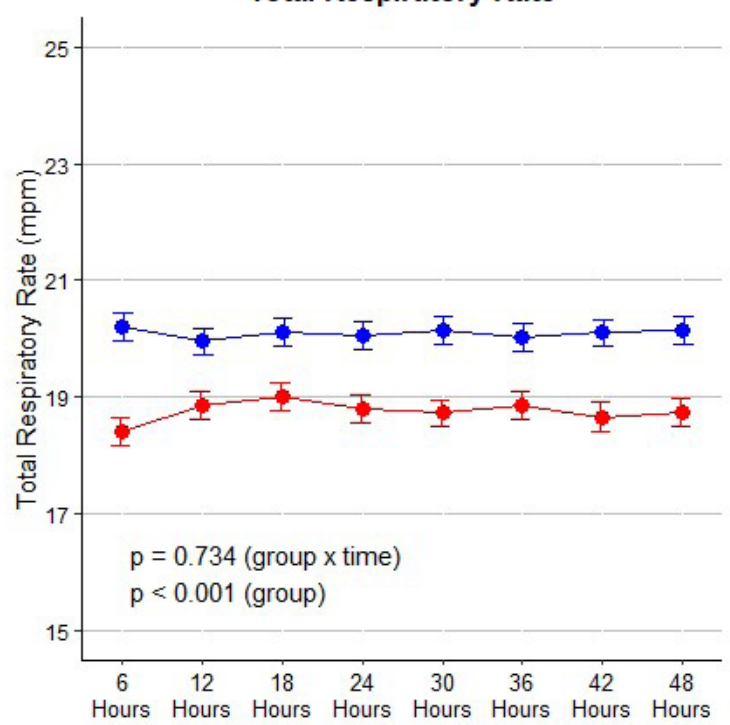

Figure S5 Measurements of ventilatory parameters every 6 hours for the first 48 hours of ventilation according to more strict groups. Circles and bars are mean and $95 \%$ confidence interval. Mixed-effect longitudinal models with random intercept for patients and with group, time and the interaction of group $\mathrm{x}$ time as fixed effects. $\mathrm{P}$ values for the group reflect the overall test for difference between groups across the 48 hours while $\mathrm{P}$ values for the group $\mathrm{x}$ time interaction evaluate if change over time differed by group. 
Table S8 Unadjusted analyses for the primary and secondary outcomes according to more strict groups

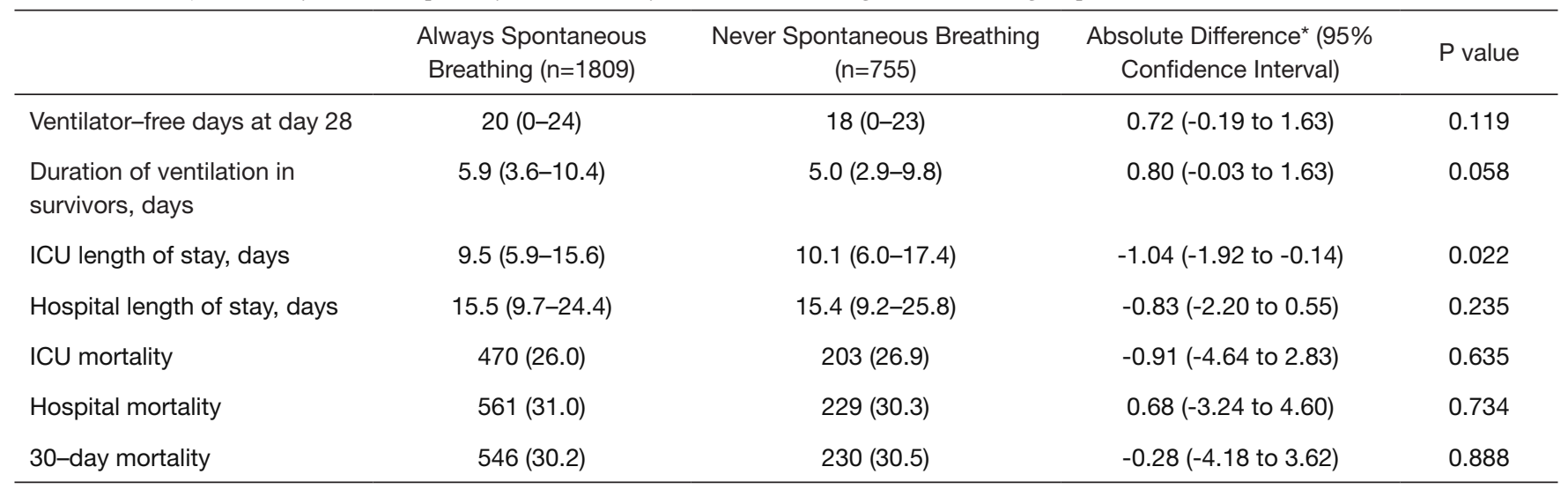

Data are median (quartile $25 \%$ - quartile $75 \%$ ) or N (percentage). ICU: intensive care unit. * absolute difference from a univariable mixedeffect linear model with year as random effect; ${ }^{a}$ effect estimate is mean difference; ${ }^{b}$ effect estimate is risk ratio.

Table S9 Adjusted analyses for the primary and secondary outcomes according to more strict groups

\begin{tabular}{|c|c|c|c|c|}
\hline & $\begin{array}{l}\text { Always Spontaneous } \\
\text { Breathing }(n=1809)\end{array}$ & $\begin{array}{l}\text { Never Spontaneous } \\
\text { Breathing }(n=755)\end{array}$ & $\begin{array}{c}\text { Absolute Difference*,** } \\
\text { (95\% Confidence Interval) }\end{array}$ & $P$ value \\
\hline Ventilator-free days at day 28 & $20(0-24)$ & $18(0-23)$ & 0.96 (0.20 to 1.72$)$ & 0.014 \\
\hline $\begin{array}{l}\text { Duration of ventilation in } \\
\text { survivors, days }\end{array}$ & $5.9(3.6-10.4)$ & $5.0(2.9-9.8)$ & $0.77(-0.16$ to 1.70$)$ & 0.109 \\
\hline ICU length of stay, days & $9.5(5.9-15.6)$ & $10.1(6.0-17.4)$ & $-0.86(-1.83$ to 0.10$)$ & 0.080 \\
\hline ICU mortality & $470(26.0)$ & $203(26.9)$ & $-1.27(-4.40$ to 1.86$)$ & 0.428 \\
\hline Hospital mortality & $561(31.0)$ & $229(30.3)$ & $-1.02(-4.19$ to 2.13$)$ & 0.530 \\
\hline 30-day mortality & $546(30.2)$ & $230(30.5)$ & $-1.66(-4.86$ to 1.54$)$ & 0.313 \\
\hline
\end{tabular}

Data are median (quartile $25 \%$ - quartile $75 \%$ ) or N (percentage). ICU: intensive care unit. * absolute difference from a multivariable mixedeffect linear model with year as random effect and adjusted for: age, gender, weight, initial diagnosis, Elixhauser comorbidity score, use of vasopressor in the first day, limitation of support, SAPS II, OASIS, SOFA at day 1, heart rate at day 1 and 2, mean arterial pressure at day 1 and 2, and $\mathrm{SpO}_{2} / \mathrm{FiO}_{2}$ at day 1 and 2; ${ }^{* *}$ continuous variables were standardized before inclusion to improve convergence; ${ }^{a}$ effect estimate is mean difference; ${ }^{b}$ effect estimate is risk ratio. 